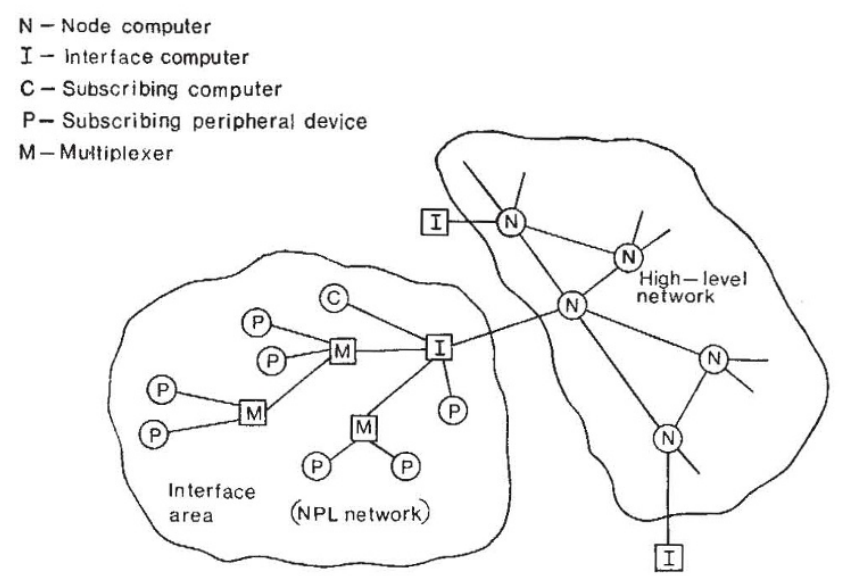

The NPL system as it would be linked to a national data transmission service (right) made up of a trunk network connected by computers at the nodes.

provides at NPL. Although the extent of the network is only about one mile by half a mile, excluding the link to Feltham, it includes most of the features that might be included in a corner of a large scale data transmission network covering Britain. The switching computer would then act as an interface with the national network, routing data into the national network for transmission to other parts of the country and extracting data from the national net for distribution to the correct terminal (see diagram).

Basically this is the system that Dr Davies and his colleagues at NPL would like to see the Post Office adopt, although Dr Davies would probably agree that the network as it stands at the laboratory is still unpolished. There is plenty of scope for miniaturization of the bulky modules that were on show this week, for example. Only a few years ago, however, those people who were prophesying a boom in the demand for data transmission facilities were accusing the Post Office of laggardliness, although since then the Post Office has instituted a market survey of the requirements, which was completed a few months ago. At present the Post Office is discussing various aspects of a national system with those in industry and elsewhere who would want to use it. Even so, any sense of urgency that may be there is hard to discern and the progress of the NPL system will be a valuable stimulus. As yet the Post Office has not committed itself, but a net similar to that proposed by NPL is thought to be likely. The question of a national network is urgent because already several different incompatible systems have been installed-those run by the banks, for example.

At present data transmission in Britain is by way of the ordinary telephone system, using devices called modems controlled by the Post Office as terminals. At present there are something like 14,000 of these terminals, and for the moment the number seems to be doubling each year. But it is clear that the telephone system as it stands is not the best basis on which to graft a data transmission system. For one thing, with the advent of multi-access computers which encourage dialogues between the computer and its users, connexions have to be maintained for comparatively long times even though for much of the time no messages are being exchanged. In the national system proposed by the data communications group at
NPL there is a trunk network of fast digital links with switching computers at the nodes and interface computers to link with the local network. The data are handled in small packets each coded with instructions as to the route it should follow.

\section{CONSERVATION Birds and Planes Don't Mix}

Wiтн European Conservation Year in full swing, it would seem a backward step to choose Foulness as the third London airport. This, at least, is the conviction of British ornithologists who feel that Foulness, situated at the mouth of the Thames estuary, would have a more worthwhile future as a nature reserve and national park.

A hundred years of restricted access to the ranges at Foulness - they are owned by the military authorities -means that Foulness now contains the largest complex of undisturbed salt marshes in south-east England and the largest bed of eel grass in western Europe. Groups of ornithologists have recently been studying the area and Dr Peter Rudge of the National Hospital, London, reports his finding in the current issue of British Birds (63, No. 2, 1970). Foulness is already providing a welcome habitat to some birds in danger of extinction. A fifth of all dark-bellied Brent geese winter at Foulness; it also supports one of the largest remaining breeding colonies of the little tern and a winter flock of Lapland buntings. Large numbers of the commoner species such as waders and gulls use Foulness when migrating southwards and ornithologists feel that it will have an even bigger part to play as more and more similar land throughout the world is reclaimed.

The risk of birds striking aircraft is a factor always to be taken into account when siting a new airport, and here the ornithologists feel they have a strong point. They claim that the risk of bird-strikes is nine times greater at Foulness than at either of the alternative inland sites. If this figure proves correct it could be a determining factor, for the cost of bird-strikes can be very high-only last year a Boeing 707 hit a flock of geese while taking off from Sydney airport and repairs cost a million dollars. The Royal Society for the Protection of Birds has been putting the ornithologists' case before the Roskill Commission on the third London airport, and this week Mr Peter Scott, chairman of the World Wildlife Fund, presented further evidence on the need for conservation of Foulness. The commission's final recommendation will not be known for another six months.

\section{SCIENCE POLICY SRC does its Sums}

LIKE all the committees of the Science Research Council, the Mathematics Committee is giving thought to the SRC policy of selectivity. To begin with, the committee, under the chairmanship of Professor W. H. Cockcroft (University of Hull), has appointed three specialist panels to look at differential equations, engineering mathematics, and, most recently, numerical analysis. These are areas which the Mathematics Committee has singled out as important to mathematics or its applications, but which are under- 